\title{
Effects on oxygenation and tissue perfusion of preoperative administration of levosimendan in hip fractures and left ventricular dysfunction
}

Maria C Martín Lorenzo ( $\nabla$ mcmartin-lorenzo@hotmail.com )

Hospital Universitario de Canarias https://orcid.org/0000-0002-6859-5755

Vanesa González Fariña

Hospital Universitario de Canarias

Nuría Montón Giménez

Hospital Universitario de Canarias

Jorge Solera Marín

Hospital Universitario de Canarias

José A. Reboso Morales

Hospital Universitario de Canarias

\section{Research}

Keywords: cardiovascular risk, left ventricular dysfunction, hip fractures, levosimendan

Posted Date: April 12th, 2021

DOl: https://doi.org/10.21203/rs.3.rs-381552/v1

License: (c) (i) This work is licensed under a Creative Commons Attribution 4.0 International License. Read Full License 


\section{Abstract}

Background: Hip fracture is common in elderly and has high morbidity and mortality. Many present left ventricular dysfunction, the use of inotropics may reduce perioperative cardiovascular complications. The objective of this study is to evaluate the safety and efficacy of a perioperative hemodynamic optimization protocol based on goal-guided therapy with levosimendan in these patients.

Methods: In this prospective study 19 patients with LVEF $<45 \%$ were recruited forhip surgery. They received an infusion of levosimendan $24 \mathrm{~h}(0.1 \mu \mathrm{g} / \mathrm{kg} / \mathrm{min})$ before surgery. Hemodynamic, oxygenation, tissue perfusion and analytical parameters; and ultrasound measurements of cardiac function were obtained before and at 24, 48 hours and 7 days later.

Results: Patients mean age was $86 \pm 7$ years. Both cardiac index, from $2.9 \pm 0.6 \mathrm{~L} \cdot \mathrm{min}^{-1} \mathrm{~m}^{-2}$ at baseline to $3.7 \pm 0.8 \mathrm{~L} \cdot \mathrm{min}^{-1} \mathrm{~m}^{-2}(P<0.001)$ and stroke volume index, from $36 \pm 10$ to $44 \pm 8 \mathrm{~mL} / \mathrm{m}^{-2}(P=0.003)$ increased significantly at $24 \mathrm{~h}$ after drug initiation and remained significantly increased for $48 \mathrm{~h}$. Systemic vascular resistance index decreased significantly (from $2302 \pm 726$ dyn.s.cm ${ }^{-5} \mathrm{~m}^{-2}$ to $1676 \pm 530$ dyn.s. $\left.\mathrm{cm}^{-5} \mathrm{~m}^{-2}, P<0.001\right)$. Ejection fraction and left ventricular outflow tract velocity time integral also increased without reaching significance. A decrease in the NT-proBNP values was observed without statistical significance. Troponin I decreased non-significant until day 7 , from $0.143 \pm 0.42 \mathrm{pg} / \mathrm{mL}$ to 0.113 $\pm 0.15 \mathrm{pg} / \mathrm{mL}(P=0.17)$. $\mathrm{DO}_{2}$ increased significantly in parallel to $\mathrm{Cl}$ from $751 \pm 196 \mathrm{~mL} / \mathrm{min}$ to $854 \pm 340$ $\mathrm{mL} / \mathrm{min}(P=0.04)$ at $48 \mathrm{~h}$, while $\mathrm{O}_{2}$ ER decreased significantly during infusion, $36 \pm 7 \%$ to $32 \pm 8 \%$ ( $P$ $=0.04) \mathrm{ScvO}_{2}$ significantly increased from $61 \pm 7 \%$ to $69 \pm 8 \%(P=<0.001) 48 \mathrm{~h}$ after infusion.

Conclusions: The implementation of a preoperative optimization protocol based on goal-directed therapy with levosimendan in patients with left ventricular dysfunction and hip fractures did not present major complications. An improvement in perioperative haemodynamic parameters and also in the balance between oxygen delivery and consumption at tissue level was found. Levosimendan decreased mortality a year with respect to a retrospective case registry.

\section{Introduction}

Hip fractures in the elderly are one of the most frequent causes of hospital admissions being a great challenge for health systems. Despite surgical advances and perioperative care, this group of patients still have a high morbidity and mortality ${ }^{1}$. Many patients undergoing hip surgery have coexisting comorbidities. Cardiovascular diseases are present in $25 \%$ of cases and heart failure in $15-18 \%^{2}$. The most important complication in hip surgery is acute decompensation of chronic heart failure (CHF), with a mortality of $65 \%$ at 30 days and $92 \%$ per year. $^{2}$

To reduce morbidity and mortality, efforts should be directed to preoperative evaluation and subsequent optimization. Surgery produces a systemic inflammatory response with the release of mediators and catecholamines leading to a substantial increase in oxygen consumption $\left(\mathrm{VO}^{2}\right)$. Most healthy patients can 
meet the increased oxygen demand raising their cardiac output (CO). However, elderly may not be able to face an increase in $\mathrm{CO}$ to the required level. So, if cardiac systolic dysfunction is present, one therapeutic option is to improve myocardial contractility. To optimize cardiac function, positive inotropes are often used. However, the use of beta-adrenergic agonists and phosphodiesterase inhibitors may have same disadvantages. They can cause an increase in intracellular calcium that increases myocardial VO2 and also have an arrhythmogenic effect. ${ }^{3-4}$

In recent years, special attention has been paid to the use of levosimendan in the perioperative period. This calcium sensitizer increases myocardial contractility, has vasodilatory and cardioprotective properties through the activation of adenosine triphosphate-dependent potassium channels. One of its metabolites (OR-1896) is active more than one week after a single intravenous administration. This may be beneficial in in patients with left ventricular dysfunction (LVD) undergoing hip fracture surgery to reduce cardiovascular complications. ${ }^{5}$ Several studies in cardiac surgery ${ }^{6-9}$ have stablished a favourable haemodynamic effect as well as its safety and efficacy. However, reports about the use of levosimendan in hip fractures are scarce but with encouraging results, like reported by Ponschab et al. ${ }^{10}$ demonstrating an increase in cardiac index $(\mathrm{Cl})$ and stroke volume index (SVI). A better cardiac performance can improve perfusion at different organs. Obviously, the presence of a hip fracture did not change the basic pharmacologic of the drug, but it has not been studied if the improvement in cardiovascular function is accompanied by a better peripheral oxygenation and tissue perfusion. Cardiac function can be evaluated through two-dimensional transthoracic echocardiographic parameters focusing in systolic performance and biomarkers according ESC guides.

We hypothesized if the implementation of a preoperative optimization protocol based in a goal-directed therapy may improve peripheral oxygenation and tissue perfusion in high risk cardiac patients. The main objective is to develop and evaluate the safety and efficacy of a perioperative hemodynamic optimization protocol including the administration of levosimendan in patients with left ventricular dysfunction $(\mathrm{LVEF}<45 \%)$ and hip fracture. Secondary objectives were to evaluate the incidence of major perioperative complications and mortality at 30 days, 2, 3, 6 months and a year after surgical treatment.

\section{Methods}

\section{Study Population}

The investigation was approved by the Clinical Research Ethics Committee of the Hospital Universitario de Canarias (Spain). Registration was completed at ClinicalTrials.gov (NCT02972918). This clinical study was conducted in accordance with the standards of good clinical practice for medical product testing in the European Community and the Declaration of Helsinki on medical research involving human subjects. All patients received written informed consent before operation.

In this prospective single-arm trial to evaluate the security and efficacy of a new protocol, a total of 19 patients with left ventricular dysfunction and hip fracture undergoing major hip surgery from a single centre were included. All selected cases fulfilled the diagnostic criteria for left ventricular dysfunction 
defined by biochemical and echocardiographic parameters defined in our protocol. The inclusion criteria were patients with proximal femur fracture who required semi-urgent surgery (48h to $72 \mathrm{~h}$ ) with left ventricular dysfunction. This was defined by LVEF $<45 \%$, assessed by preoperative two-dimensional transthoracic echocardiographic (TTE) and elevated basal values of NT Pro-BNP according to age.

Exclusion criteria were age under 18 , atrial fibrillation or tachycardia with rapid ventricular response $(>140$ bpm), history of Torsade de Pointes, severe aortic stenosis, obstructive or severe restrictive cardiomyopathy, systolic blood pressure $<85 \mathrm{mmHg}$, severe kidney disease (creatinine clearance $<30 \mathrm{~mL}$ $\min ^{-1}$ ) or severe liver failure (class $\mathrm{C}$ of the Child-Pugh classification).

\section{Preoperative and Introperative Protocol}

The screening for inclusion was made in the emergency department every patient with hip fracture had a preoperative assessment. In addition, to evaluate, we used several scoring systems that try to define the risk of perioperative complications. Revised Cardiac Risk Index, published by Lee. ${ }^{11}$ others were the functional class according to NYHA, the ASA and the Charlson comorbidity index. After preanesthesia evaluation, subjects recruited were admitted to the PACU (Post-Anaesthesia Care Unit) at least $24 \mathrm{~h}$ before surgery. In the PACU, prior to surgery patient monitoring consisted of ECG, pulse oximetry and hemodynamic parameters. A catheter was inserted in one radial artery to obtain blood gas test samples and for hemodynamic monitoring with the Pulsioflex® system (ProAQT, PULSION Medical Systems SE, Munich, Germany). An ultrasound-guided central venous catheter was inserted in the internal jugular vein for central venous pressure (CVP) monitoring and venous blood gas analysis. Bladder catheterization was performed to control diuresis.

Hemodynamic, oxygenation and tissue perfusion parameters were measured before levosimendan infusion (basal) and 4, 12, 24 and $48 \mathrm{~h}$ later. Biochemical determinations, NT-proBNP (N-terminal pro-Btype natriuretic peptide), troponin $\mathrm{I}$, and ultrasound parameters were obtained before the beginning of levosimendan administration and $24 \mathrm{~h}, 48 \mathrm{~h}$ and 7 days later. A TTE exam was performed using a LOGIQe ultrasound machine (General Electric, Hamburg, Germany). Two anaesthesiologists carried out echocardiographic assessment with specific training in echocardiography in critical patients. The echocardiographic measurements recorded were LVEF according to the modified Simpson biplane method, tricuspid regurgitation systolic pressure gradient (TRPG), systolic pulmonary artery pressure (SPAP) and left ventricular outflow tract velocity time integral (LVOT VTI).

A levosimendan (Orion Pharma, Espoo, Finland, Simdax ${ }^{\circledR}$ ) intravenous infusion at $0.1 \mu \mathrm{g} \mathrm{kg}^{-1} \mathrm{~min}^{-1}$ without loading dose was administered to all patients during $24 \mathrm{~h}$ prior to surgery. No other inotropes were used during levosimendan treatment. The hypotensive response expected from levosimendan due to its vasodilator effect was contemplated in the hemodynamic optimization protocol.

If hypotension occurred (MAP $<65 \mathrm{mmHg}$ ), three successive actions were considered. First administration of $250 \mathrm{~mL}$ of $0.9 \%$ Saline iv in 30 minutes, second a norepinephrine infusion (initial dose of $0.05 \mathrm{ug} \mathrm{kg}^{-1}$ 
$\min ^{-1}$ ) and by last decrease levosimendan infusion rate to $0.05 \mu \mathrm{gg}^{-1} \mathrm{~min}^{-1}$.

Patients were optimized according GDT protocols while they were in the PACU. This protocol is based on predefined targets for $\mathrm{MAP}, \mathrm{Hb}, \mathrm{SpO}_{2}, \mathrm{DO}_{2}$ and $\mathrm{SvcO} 2$ (Figure 1).

The primary outcome of the study was the change in cardiac function through hemodynamic parameters (IC, SVI, SVRI), laboratory tests (Troponin I and NT-proBNP) and echocardiographic (LVEF, VTI, SPAP) and effects on oxygen transport and tissue perfusion. Secondary endpoints were mortality at 3, 6 and 12 months of inclusion in the study.

To direct fluid therapy and predict fluid responsiveness in spontaneously breathing patients, the passive leg-raising maneuver (PRL) was used. A PLR test is positive if the SVI increased by> $10 \%$ (responders). ${ }^{12}$ SVI was measured by pulse contour analysis by Pulsioflex. In the case of a positive PLR test, a volume expansion was administered with $250 \mathrm{ml}$ of saline.

$\mathrm{SpO}_{2}$ targets $>94 \%$ and $\mathrm{Hb}>90 \mathrm{~g} / \mathrm{L}$, for the optimization of $\mathrm{DO}_{2}$ and to maintain an adequate $\mathrm{SvO}_{2}$.

In addition, patients received therapeutic indications that the clinician in charge considered appropriate. The surgery took place within the first two days after the end of levosimendan infusion. The specific technique and anaesthetic management was at the discretion of the assigned anaesthesiologist.

Once intervened, the patients were transferred to the PACU for observation during the first $24 \mathrm{~h}$. The immediate postoperative adverse effects of the use of the clinical protocol were registered. Moreover, the clinical situation, major complications and mortality, of every patient was confirmed 30 days after the intervention.

After discharge from hospital follow-up was performed using electronic medical records and structured and conducted telephone interviews. To assess mortality in the medium and long term, follow-ups were performed after 30 days, 2, 3, 6 months and a year after surgical treatment.

The result of optimization with levosimendan was considered effective when the objective parameters improved significantly $>20 \%$. The parameters studied were hemodynamic (increase in IC, SVI and decrease in systemic vascular resistance), echocardiographic (increase in LVEF, decrease in SPAP) and biochemical (decrease in NT-proBNP levels and troponin I).

\section{Statistical Analyses}

Qualitative variables are expressed with absolute frequencies and percentages and quantitative and ordinal variables with means and standard deviations. Proportion comparisons were conducted with Fisher's chi-square or exact tests, as appropriate. Comparisons of two groups in quantitative and ordinal variables were performed with Mann-Whitney tests. Variables with repeated measurements were compared with Friedman and Wilcoxon tests, for more than two groups and for two groups respectively. Survival 
curves were constructed using the Kaplan-Meier method and group comparisons were made using the log rank method (Mantel-Cox).

Comparisons of groups controlling for confounding variables were performed with ANOVA, as appropriate. Probability values less than 0.05 were considered significant. Analyses were performed with SPSS version 17.0 (Chicago, IL).

The researchers collected the data. The database included range and internal consistency rules to ensure quality control of the data.

\section{Results}

During the study period, nineteen patients ASA III (84\%) and IV (16\%) undergoing urgent hip fracture repair and LVD were recruited and preoperatively optimized with levosimendan. The mean \pm SD of age was $86 \pm$ 7 years. The demographic and clinical characteristics of the patients are shown in Table 1.

Table 1 Baseline clinical characteristics of the patients

\begin{tabular}{lc}
\hline Baseline clinical characteristics of the patients & $\mathrm{n}=19$ \\
\hline Age [median (IQR); yr] & $86(77-93)$ \\
\hline Female sex [n (\%)] & $11(58)$ \\
\hline Charlson comorbidity index & $5 \pm 3$ \\
\hline ASA (\%) & $16(84)$ \\
III & $3(16)$ \\
\hline IV & $9(47)$ \\
\hline NYHA III-IV & $2(10)$ \\
\hline Lee RCRI (\%) & $7(37)$ \\
2 & $8(42)$ \\
3 & $2(10)$ \\
\hline Hypertension [n (\%)] & $14(74)$ \\
\hline Diabetes [n (\%)] & $9(47)$ \\
\hline Dislipemia [n (\%)] & $14(21)$ \\
\hline Atrial fibrillation[ [n (\%)] & $12(63)$ \\
\hline Chronic obstructive pulmonary disease [n (\%)] & $6(32)$ \\
\hline Chronic kidney disease [n (\%)] & $4(\%)$ \\
\hline Congestive heart failure [n (\%)] & \\
\hline & \\
\hline
\end{tabular}

ASA, American Society of Anesthesiologists classification; NYHA, New York Heart Association;

RCRI, revised cardiac risk index score.

Haemodynamic effects on patients from baseline to $48 \mathrm{~h}$ after the beginning of levosimendan infusion are shown in Table 2. The administration of levosimendan produced a statistically significant increase in $\mathrm{Cl} 48$ 
h after infusion compared to pre-infusion values, from a mean value of $2.9 \pm 0.6 \mathrm{~L}$. $\mathrm{min}^{-1} \mathrm{~m}^{-2}$ to $3.7 \pm 0.8$ L. $\min ^{-1} \mathrm{~m}^{-2}(P<0.001)$. Heart rate $(\mathrm{HR})$ remained without significant variations.

Table 2 Comparison of hemodynamic characteristics at baseline, 24 and 48 hour after starting of levosimendan infusion.

\begin{tabular}{|c|c|c|c|c|c|}
\hline & Baseline & $24 \mathrm{~h}$ & $48 \mathrm{~h}$ & $P$ global & $\begin{array}{c}P \\
\text { baseline vs } 48 \mathrm{~h}\end{array}$ \\
\hline HR (bmp) & $79 \pm 16(n=19)$ & $80 \pm 15$ & $85 \pm 16$ & 0,23 & - \\
\hline MAP (mmHg) & $85 \pm 15(n=19)$ & $77 \pm 13$ & $76 \pm 12$ & 0,004 & 0,01 \\
\hline CVP (mmHg) & $11 \pm 2(n=19)$ & $6 \pm 3$ & $8 \pm 3$ & 0,34 & - \\
\hline $\mathrm{CI}\left(\mathrm{L} \min 1 \mathrm{~m}^{-} 2\right)$ & $2,9 \pm 0,6(n=18)$ & $3,4 \pm 0,7$ & $3,7 \pm 0,8$ & $<0,001$ & $<0,001$ \\
\hline SVI (mL m ${ }^{-}$2) & $36 \pm 10(\mathrm{n}=19)$ & $42 \pm 9$ & $44 \pm 8$ & $<0,001$ & 0,003 \\
\hline SVRI (dyn s cm 5 m 2) & $2302 \pm 726(n=19)$ & $1777 \pm 448$ & $1676 \pm 530$ & $<0,001$ & $<0,001$ \\
\hline $\mathrm{CPI}\left(\mathrm{w}^{-} 1 \mathrm{~m}^{-} 2\right)$ & $0,6 \pm 0,2(n=17)$ & $0,6 \pm 0,1$ & $0,7 \pm 0,1$ & 0,29 & - \\
\hline
\end{tabular}

CI, cardiac index; CPI, Cardiac power index; CVP, central venous pressure; HR, heart rate; MAP, mean arterial pressure; NT proBNP, I terminal pro-B-type natriuretic peptide; SVI, stroke volume index; SVRI, systemic vascular resistances index.

The increase in CI was parallel to the increase in SVI. The SVI increased significantly $24 \mathrm{~h}$ after the onset of infusion and remained significantly increased for $48 \mathrm{~h}$ after infusion, $36 \pm 10 \mathrm{~mL} / \mathrm{m}^{-2} \mathrm{vs} 44 \pm 8 \mathrm{~mL} / \mathrm{m}^{-2}(P$ $=0.003$ ). Changes in $\mathrm{Cl}$ and SVI are shown in Figure 2.

Levosimendan infusion produced a significant decrease of systemic vascular resistance index (SVRI) from a basal mean value of $2302 \pm 726$ dyn.s.cm. ${ }^{-5} \mathrm{~m}^{-2}$ to $1676 \pm 530$ dyn.s.cm. ${ }^{-5} \mathrm{~m}^{-2}$ after $48 \mathrm{~h}(P<0.001)$. Similarly, there was a significant decrease in MAP during the $48 \mathrm{~h}$ after infusion from $85 \pm 15 \mathrm{mmHg}$ to 76 $\pm 12 \mathrm{mmHg}(P<0.004)$. According to protocol, in 6 cases $31,5 \%$ an infusion of $250 \mathrm{~mL}$ of $0.9 \%$ saline was insufficient to avoid hypotension and a noradrenaline infusion in a range between $0.05-0.15 \mu \mathrm{kg}^{-1} \mathrm{~min}^{-1}$ was necessary to maintain PAM $>65 \mathrm{mmHg}$. The average duration of noradrenaline infusion was less than 36 hours. Levosimendan showed no significant effect on CVP, HR and CP, whose values remained within narrow limits.

Ultrasound measurements of changes in cardiac function during levosimendan infusion are presented in Table 3. A sustained increase in both LVEF and VTI from baseline levels was observed at $24 \mathrm{~h}, 48 \mathrm{~h}$ and 7 days, almost reaching statistical significance. LVEF at day 7 compared to baseline increased but did not reach statistical significance, $34 \pm 7 \%$ at baseline vs $42 \pm 14 \%(P=0.07)$. Likewise, the LVOT VTI showed an increase on the 7th day after the end of the infusion, without reaching significance $16 \pm 5 \mathrm{~cm}$ vs $17 \pm 5$ $\mathrm{cm}(P=0.05)$. Statistically significant differences were found in the measurements of TRPG during levosimendan infusion and on the 7th day of completion, $17 \pm 15 \mathrm{mmHg}$ vs $7 \pm 8 \mathrm{mmHg}(P=0.03)$. However, SPAP estimated with ultrasound exam did not decrease significantly comparing the 4 measurements, from $24 \pm 16 \mathrm{mmHg}$ to $15 \pm 10 \mathrm{mmHg}(P=0.32)$. 
Levels of NT-proBNP and troponin I are shown in Table 3. In Figure 3 are represented the evolution of plasma levels of NT-proBNP and troponin I from the beginning to the seventh day after the end of the infusion. Baseline levels of NT-proBNP were high in all cases as expected in left ventricular dysfunction patients. The mean \pm SD at hospital admission was $9335 \pm 10910 \mathrm{pg} / \mathrm{mL}$. A decrease in the NT-proBNP value was observed from baseline values to $6112 \pm 8648 \mathrm{pg} / \mathrm{mL} 24 \mathrm{~h}$ after. The decrease was maintained at the 7 th day, $7067 \pm 8274 \mathrm{pg} / \mathrm{mL}$, without statistical significance $(P=0.08)$. Levosimendan infusion produced a non-significant decrease in baseline troponin I values from $0.143 \pm 0.42 \mathrm{pg} / \mathrm{mL}$ to $0.113 \pm 0.15 \mathrm{pg} / \mathrm{mL}$ at day $7(P=0.17)$.

Table 3 Comparison of echocardiographic characteristics at baseline, 24 hour and 7 days after the start of levosimendan infusion.

\begin{tabular}{|c|c|c|c|c|c|}
\hline & Baseline & $24 \mathrm{~h}$ & $48 \mathrm{~h}$ & 7 day & $P$-value \\
\hline \multirow[t]{2}{*}{ LVEF (\%) } & $34 \pm 7$ & $39 \pm 12$ & $40 \pm 14$ & $42 \pm 14$ & 0,07 \\
\hline & $(\mathrm{n}=19)$ & $(n=16)$ & $(\mathrm{n}=16)$ & $(n=16)$ & \\
\hline \multirow[t]{2}{*}{ VTI (cm) } & $16 \pm 5$ & $(n=13)$ & $18 \pm 6$ & $17 \pm 5$ & 0,05 \\
\hline & $(n=15)$ & & $(n=13)$ & $(n=12)$ & \\
\hline \multirow[t]{2}{*}{ TRPG (mmHg) } & $17 \pm 15$ & $12 \pm 12$ & $11 \pm 12$ & $(n=13)$ & 0,03 \\
\hline & $(n=16)$ & $(n=15)$ & $(\mathrm{n}=14)$ & & \\
\hline \multirow[t]{2}{*}{ SPAP (mmHg) } & $24 \pm 16$ & $18 \pm 13$ & $18 \pm 11$ & $15 \pm 10$ & 0,3 \\
\hline & $(\mathrm{n}=16)$ & $(n=15)$ & $(n=13)$ & $(n=5)$ & \\
\hline NT-ProBNP (pg & $9335 \pm 10910$ & $6112 \pm 8648$ & - & $7067 \pm 8274$ & 0,08 \\
\hline \multicolumn{6}{|l|}{$\left.\mathrm{mL}^{-} 1\right)$} \\
\hline Troponina I & $0,143 \pm 0,42$ & $0,149 \pm 0,33$ & - & $0,113 \pm 0,15$ & 0,17 \\
\hline (ng $1 \mathrm{~mL})$ & & & & & \\
\hline
\end{tabular}

LVEF, left ventricular ejection fraction; SPAP, pulmonary artery pressure; TRPG, tricuspid regurgitation systolic pressure gradient; VTI, velocity time integralu.

Table 4 shows the mean \pm SD of the oxygenation and tissue perfusion parameters of all patients. Basal mean haemoglobin $(\mathrm{Hb})$ was $114 \pm 18 \mathrm{~g} / \mathrm{L}$ and $101 \pm 14 \mathrm{~g} / \mathrm{L} 48$ hours later, when patients have been operated, with a statistically significant decrease $(P=0.001)$.

Table 4 Comparison of oxygenation parameters and tissue perfusion characteristics at baseline, $24 \mathrm{~h}$ and $48 \mathrm{~h}$ after the start of Levosimendan infusion. 


\begin{tabular}{|c|c|c|c|c|c|}
\hline & Baseline & $24 \mathrm{~h}$ & $48 \mathrm{~h}$ & $P$-value & $\begin{array}{c}P \\
\text { baseline vs } 48 \mathrm{~h}\end{array}$ \\
\hline $\mathrm{Hb}\left(\mathrm{g} \mathrm{L}^{-} 1\right)$ & $11,4 \pm 1,8(\mathrm{n}=19)$ & $10,8 \pm 1,4$ & $10,1 \pm 1,4$ & $<0,001$ & 0,001 \\
\hline $\mathrm{pH}$ & $7,40 \pm 0,05(\mathrm{n}=19)$ & $7,39 \pm 0,06$ & $7,37 \pm 0,07$ & 0,01 & 0,009 \\
\hline $\mathrm{PaO}_{2}(\mathrm{mmHg})$ & $88 \pm 27(n=19)$ & $99 \pm 20$ & $96 \pm 20$ & 0,03 & 0,1 \\
\hline $\mathrm{PaCO}_{2}(\mathrm{mmHg})$ & $38,3 \pm 9 \quad(n=19)$ & $39 \pm 7$ & $40,4 \pm 9$ & 0,18 & - \\
\hline $\mathrm{PvCO}_{2}(\mathrm{mmHg})$ & $46 \pm 9(n=19)$ & $45 \pm 7$ & $46 \pm 8$ & 0,48 & - \\
\hline $\mathrm{DvaPCO}_{2}(\mathrm{mmHg})$ & $8 \pm 2(n=19)$ & $6 \pm 4$ & $6 \pm 2$ & 0,19 & - \\
\hline$\overline{\mathrm{SaO}_{2}(\%)}$ & $94 \pm 4 \quad(n=19)$ & $96 \pm 2$ & $96 \pm 2$ & 0,01 & 0,06 \\
\hline p50 (mmHg) & $28 \pm 3(n=19)$ & $27 \pm 3$ & $27 \pm 2$ & 0,33 & - \\
\hline Lactate (mmol L ${ }^{-}$) & $0,94 \pm 0,4(\mathrm{n}=19)$ & $1 \pm 0,4$ & $0,92 \pm 0,4$ & 0,76 & - \\
\hline $\mathrm{SvO}_{2}(\%)$ & $61 \pm 7(n=19)$ & $65 \pm 10$ & $69 \pm 8$ & 0,002 & $<0,001$ \\
\hline $\mathrm{CaO}_{2}\left(\mathrm{~mL} \mathrm{dL}{ }^{-1} 1\right)$ & $15 \pm 3(n=19)$ & $14 \pm 3$ & $14 \pm 2$ & 0,15 & - \\
\hline $\mathrm{CvO}_{2}\left(\mathrm{~mL} \mathrm{dL}{ }^{-} 1\right)$ & $10 \pm 2(n=19)$ & $10 \pm 2$ & $9 \pm 2$ & 0,42 & - \\
\hline $\mathrm{DO}_{2}\left(\mathrm{~mL} \min { }^{-} 1\right)$ & $751 \pm 196(n=19)$ & $854 \pm 267$ & $855 \pm 340$ & 0,04 & 0,12 \\
\hline $\mathrm{ERO}_{2}(\%)$ & $36 \pm 7(n=19)$ & $33 \pm 9$ & $32 \pm 8$ & 0,04 & 0,03 \\
\hline
\end{tabular}

CI, cardiac Index; CVP, central venous pressure; HR, heart rate; MAP, mean arterial pressure; SVI, stroke volume index; SVRI, systemic vascular resistance index; $\mathrm{O}_{2} \mathrm{ER}$, oxygen extraction ratio

A significant decrease in $\mathrm{pH}$ from $7.40 \pm 0.05$ to $7.37 \pm 0.07(P=0.01)$ was observed after $48 \mathrm{~h}$ of levosimendan infusion. Oxygen delivery $\left(\mathrm{DO}_{2}\right)$ increased significantly in parallel to $\mathrm{Cl}$ from $751 \pm 196$ $\mathrm{mL} / \mathrm{min}$ to $854 \pm 340 \mathrm{~mL} / \mathrm{min}(P=0.04)$ at $48 \mathrm{~h}$, while $\mathrm{O}_{2}$ ER decreased significantly during infusion of levosimendan, from $36 \pm 7 \%$ to $32 \pm 8 \%(P=0.04)$. Central venous oxygen saturation $\left(\mathrm{ScvO}_{2}\right)$ increased significantly from a mean basal level of $61 \pm 7 \%$ to $69 \pm 8 \%(P=<0.001) 48 \mathrm{~h}$ later.

A decrease in venous-to-arterial $\mathrm{PCO}_{2}$ difference $\left(\triangle P \mathrm{CO}_{2}\right)$ from $8 \pm 2$ to $6 \pm 2$ was also observed, without reaching statistical significance $(P=0.19)$. Levels of serum lactate in arterial blood remained unchanged after $48 \mathrm{~h}$ of levosimendan infusion, $0.94 \mathrm{mmol} / \mathrm{L} \pm 0.4 \mathrm{vs} 92 \pm 0.4 \mathrm{mmol} / \mathrm{L}(P=0.76)$. However, a significant increase in oxygen partial pressure $\left(\mathrm{PaO}_{2}\right)$ from $88 \pm 27 \mathrm{mmHg}$ to $96 \pm 20 \mathrm{mmHg}(P=0.14)$ was observed after $48 \mathrm{~h}$ of levosimendan infusion. Peripheral arterial saturation $\left(\mathrm{SpO}_{2}\right)$ values increased statistically significantly from their baseline value of $94 \pm 4 \%$ to $96 \pm 2 \%(P=0.01)$ after $48 \mathrm{~h}$ of levosimendan infusion. Arterial oxygen content $\left(\mathrm{CaO}_{2}\right)$ did not show a statistically significant increase, from a baseline level of $15 \pm 3 \mathrm{~mL} / \mathrm{dL}$ to $14 \pm 2 \mathrm{~mL} / \mathrm{dL}(P=0.15)$.

A total of 19 adverse events during the application of the protocol were collected. Mild hypotension was the most frequent adverse event observed, with a total of 6 cases (31.5\%). Other less frequent side effects are detailed below. One case (5\%) of atrial fibrillation well tolerated was recorded and reversed to sinus 
rhythm after treatment with amiodarone. Another case (5\%) of mild hypokalemia was documented. One patient (5\%) suffered from headache and another one presented nonspecific nausea and vomiting.

Follow-up of mortality in studied patients was done for 6 months after surgery. Of the nineteen patients, three $(15.7 \%)$ died in the next six months. The causes of mortality and the incidence of severe morbidity are presented in Table 5.

Table 5 Adverse events during the $24 \mathrm{~h}$ preoperative infusion

\begin{tabular}{|c|c|}
\hline Adverse events & $\mathrm{n}=19$ \\
\hline $\begin{array}{l}\text { Hypotension - n (\%) } \\
\text { Mild } \\
\text { Severe }\end{array}$ & $\begin{array}{lll}6(31,5) & & \\
\end{array}$ \\
\hline Need for vasopressors (low dose) & $6(31,5)$ \\
\hline Tachycardia - n (\%) & $3(15,7)$ \\
\hline Atrial fibrillation-n (\%) & $1(5)$ \\
\hline Hipopotasemia- n (\%) & $1(5)$ \\
\hline Nausea-n (\%) & $1(5)$ \\
\hline$\overline{\text { Vomiting } \square-\mathrm{n}(\%)}$ & $1(5)$ \\
\hline
\end{tabular}

\section{Discussion}

The main objective of this study was to evaluate the safety and efficacy of the implementation of a preoperative optimization protocol with levosimendan in elderly patients with hip fractures and LVD. Acute cardiac decompensation in patients with a pre-existing $\mathrm{CHF}$ is relatively frequent. Scoring systems to assess cardiac risk in non-cardiac procedures used in our patients confirmed a high-risk population. We report the results in patients with high levels of NT-proBNP, left ventricular dysfunction (mean \pm sd of LVEF $34 \pm 7$ ) and hip fracture in a tertiary hospital. A preoperative infusion of levosimendan at $0.1 \mu \mathrm{g} . \mathrm{kg}^{-1} \mathrm{~min}^{-}$ 1 and a GDT increased CI, SVI, LVEF and LVOT VTI. Our results confirm that the improvement in hemodynamic parameters is translated to oxygenation and tissue perfusion parameters.

Elderly patients with LVD suffer commonly acute trauma that can originate hip fractures. Once admitted to surgery repair, they face major perioperative haemodynamic alterations. These imbalances are caused by preoperative hypovolemia, diuretics, bleeding and pain. In addition, some clinical situations such as hypotension, tachycardia, inflammatory response and inadequate volume management may cause or worsen ventricular dysfunction. LVD is a highly prevalent condition in elderly patients undergoing hip fracture. Authors like Cullen et al. ${ }^{13}$ reported that patients with preoperative LVD typically suffer from more cardiovascular comorbidities and.

It has been proposed that preoperative optimization of hemodynamic parameters and increased $\mathrm{CO}$ can reduce postoperative cardiovascular complications in patients undergoing non-cardiac elective surgery. ${ }^{14}$ Some of the proposed therapeutic measures include, preload optimization, transfusion of red blood cells 
and positive inotropic drugs. The objective is to improve preoperative $\mathrm{CO}$, partially reverse cardiac dysfunction and exert a cardioprotective effect. Is generally accepted that inotropes may be used only in a situation of LVD combined with signs of end-organ hypoperfusion. ${ }^{15}$ Several studies suggest that prophylactic levosimendan in cardiac surgery is safe and improves hemodynamic and pulmonary efficacy, reduces the need for inotropic drugs, ventilatory support and improves survival. ${ }^{4}$ However, there are few studies in CHF patients in non-cardiac surgery. Levosimendan appears to be a suitable inodilator for preoperative cardiac optimization in CHF patients undergoing hip surgery. A meta-analysis about the effect of inotropes and vasopressors on mortality reported that levosimendan was the only drug associated with improvement in survival. ${ }^{16}$

With respect to the safety of infusion of levosimendan, no major complications were detected despite that mean age of the recruited subjects in our study was $86 \pm 7$ years. Lacking a control group makes it difficult to identify specifically those side-effects uniquely attributable to the study drug infusion from other complications inherent to this patient population having hip surgery. Our aim was to check the security of the application of our protocol. Hypotension was the most frequent side effect; MAP showed a statistically significant decrease it was maintained within acceptable limits. In the haemodynamic optimization protocol, low doses of noradrenaline were allowed if a pronounced vasodilator effect was observed. It was necessary only in 6 patients (31.5\%). The HR did not vary significantly and there was no evidence of severe arrhythmias. The Pulsion ${ }^{\circledR}$ monitor was available and GDT was used. Changes in SV induced by passive legs raising are accurate indices for predicting fluid responsiveness. An increase of SV $>10 \%$ allows predicting a positive response to volume management with high sensitivity and specificity. ${ }^{12}$

Focusing on efficiency, levosimendan at $0.1 \mu \mathrm{g} . \mathrm{kg}^{-1} \mathrm{~min}^{-1}$ during $24 \mathrm{~h}$ can be considered effective for preoperative optimization in patients with CHF. A significant increase in $\mathrm{Cl}$ and $\mathrm{SVI}$, along with a significant decrease in SVRI after $48 \mathrm{~h}$ of infusion have been reported. ${ }^{10,17}$ Our data confirmed the inotropic and vasodilatory properties of levosimendan in systemic and pulmonary circuit by ultrasound measurements. Patients showed an improvement in the left ventricular systolic function. The LVOT VTI increased and a decrease in pulmonary artery systolic pressure, but without reaching statistical significance. An increase in LVEF $(P=0.07)$ compared to basal values at $24 \mathrm{~h}$ was observed and was maintained until the seventh day after infusion. Similarly, an increase in LVOT VTI was obtained in $24 \mathrm{~h}$ and maintained, with a clear tendency to significance $(P=0.05)$. There was also a significant decrease in the tricuspid regurgitation systolic pressure gradient at $24 \mathrm{~h}$, which was maintained until seven days after levosimendan administration. These results are consistent with several studies demonstrating that preoperative administration of levosimendan increases LVEF.8,18

The results of our study on the ability of levosimendan to increase LVEF and LVOT VTI without reaching statistical significance can be attributed to the small number of patients analysed. Results presented here are consistent with previous studies demonstrating the beneficial effects of levosimendan on cardiac and haemodynamic performance of patients undergoing non-cardiac surgery. ${ }^{10,17,18,19}$ Other attributable benefits of levosimendan are the vasodilatory properties and coronary vasodilation improves cardiac oxygenation generating a cardioprotective effect. ${ }^{20-23}$ However, in our group of patients, SPAP values 
decreased non-significantly. Previous studies confirm a drop in pulmonary pressures in both cardiac and non-cardiac surgery. ${ }^{24,25}$

The analysis of the effects on oxygenation and tissue oxygen perfusion showed a clear increased in D02 despite mean $\mathrm{Hb}$ values decreased significantly from $114 \mathrm{~g} / \mathrm{L}$ to $100 \mathrm{~g} / \mathrm{L}$ after $48 \mathrm{~h}$. This can be explained by haemodilution and intraoperative blood loss. Hemodynamic optimization clearly contributed to an improvement in tissue perfusion. This action was reflected in a significant increase of $\mathrm{ScvO} 2, \mathrm{SpO} 2$, and in the decrease of O2ER and $\triangle \mathrm{PCO}$. Several studies have found an expected significant increase in ScvO2 after levosimendan infusion $26,27,28$. The ScvO2 is directly proportional to the increase of $\mathrm{CO}$, and we found that it increased in parallel to the $\mathrm{Cl}$. ScvO2 is probably the best isolated indicator of the adequacy of D02, since it represents the amount of oxygen remaining in the blood after passing through the tissues.

We determined serum lactate in arterial blood samples values and the values were maintained within a normal range during all records.

A fact to be highlighted in this study is that after levosimendan the $\mathrm{O}_{2} \mathrm{ER}$ significant decrease and $\triangle P C \mathrm{C}_{2}$ improved, approaching statistical significance administration. Currently, we are not aware of other studies with levosimendan that have presented data of variations of $\mathrm{DO}_{2}, \triangle P \mathrm{CO}_{2}, \mathrm{O}_{2} \mathrm{ER}, \mathrm{CaO}_{2}$ and venous oxygen content $\left(\mathrm{CVO}_{2}\right)$ in patients with hip fractures and LVD. It has been established ${ }^{30}$ an inverse correlation between $\triangle P C O_{2}$ and $\mathrm{Cl} . \triangle P C O_{2}>6 \mathrm{mmHg}$ levels have been shown to be useful in the detection of persistent hypoperfusion despite the normalization of $\mathrm{ScvO}_{2}$. The effects of levosimendan on microvascular blood flow and oxygenation are not yet fully clarified. Experimental studies show that levosimendan improves microvascular oxygenation under normal conditions and in sepsis. 19,31,32 It was speculated that, in addition to its vasodilatory properties, there would be a beneficial effect of levosimendan on the endothelium, which would play a role in improving microcirculation. There are several mechanisms by which levosimendan can improve endothelial function. First, by improving systemic hemodynamic and attenuating peripheral tissue hypoperfusion, second levosimendan can lead to negative regulation of extracardiac cytokine synthesis by reducing transcriptional factors in peripheral tissues, such as the nuclear factor kappa B. ${ }^{33}$

Measurement of NT-proBNP is useful for additional heart risk assessment in the postoperative period. In case of decreased $\mathrm{CO}$ and associated end-organ failure, the use of levosimendan seems to be superior to other positive inotropic drugs. ${ }^{34}$ We observed a decrease on levels of NT-proBNP that was maintained for up to 7 days. Although there were differences in absolute values, no statistical significance was found due to the large dispersion in the data, reflected in the high standard deviation, which was above the mean. Our results point to obtained in various studies, which indicate that levosimendan produces a rapid and sustained decrease in natriuretic peptides. ${ }^{35,36}$ Regarding troponin I, the values in the patients studied presented a non-significant decrease in all of them, demonstrating a certain cardioprotective effect and a potential preconditioning action. We can say that levosimendan was generally well tolerated by patients. Most of its adverse effects are due to its dose-related vasodilator effect. ${ }^{37}$ In no case was it necessary to discontinue the infusion of the drug. A possible caution when interpreting this study could be the influence 
of the different anaesthetic technique used. The vasodilating properties of levosimendan can be potentiated by the loss of adrenergic response of spinal anaesthesia and may cause a significant decrease in MAP.

Regarding mortality evaluation, $84 \%$ of patients survived the first 6 months after discharge from hospital. This survival data is higher than Ponschab et al. ${ }^{11}$ Presented in their study $(60 \%)$. In our study, mortality at six months was lower $(15.7 \%)$ compared to that recorded (21\%) in a study in patients with hip fractures in the Canary Islands. ${ }^{38}$

Our study has some limitations. First, we recruited a limited number of patients. Surely, we did not detect all the cases who met the inclusion criteria during the recruitment period. The Trauma and Orthopaedic Service of our hospital scheduled the surgery and sometimes the patients were not fully studied at the time of surgery. So, same cases were missed. Furthermore, all candidates did not always have access to the PACU, the place where the patients were monitored preoperatively. Another limitation of our study was the lack of a control group. The local Clinical Research Ethics Committee Institutional Review Board (IRB) prevented randomization in two arms arguing ethical reasons. The IRB finally denied the request to randomize patients to placebo vs levosimendan infusion without arguing clear justifications.

Also, it can be considered that the concomitant use of noradrenaline might have influenced the global haemodynamic results. In our opinion, is unlikely that a norepinephrine infusion in low doses in some patients might have caused increases in Cl, LVEF, LVOT VTI and oxygenation parameters.

The results of the implementation of a preoperative administration of levosimendan enclosed in a goaldirected therapy optimization protocol are frankly promising. This drug has a delayed onset of action when administered as a continuous infusion that allows patients to face surgery in a better hemodynamic situation. However, the applicability of our results to a larger population must be studied, since it implies higher economic costs in personnel, in infrastructures and the way to approach this pathology with high morbidity and mortality. It is necessary to promote clinical trials with a greater number of patients to confirm our results and elaborate new guidelines in hip fractures and cardiac high-risk patients.

\section{Conclusion}

The implementation of a preoperative optimization protocol with levosimendan inpatients with left ventricular dysfunction and hip fracture improved not only perioperative haemodynamic parameters, but also the balance between oxygen delivery and consumption at tissue level.

\section{Abbreviations}

$\mathrm{CaO}_{2}$ arterial oxygen content

$\mathrm{CvO}_{2}$ : venous oxygen content 
CHF: congestive heart failure

Cl: cardiac index

CO: cardiac output

CVP: central venous pressure

$\mathrm{DO}_{2}$ : oxygen delivery

GDT: goal-directed therapy

$\mathrm{Hb}$ : haemoglobin

HR: heart rate

IRB: Institutional Review Board

LVEF: left ventricular ejection fraction

LVOT VTI: left ventricular outflow tract velocity time integral

MAP: mean arterial pressure

NT-proBNP: N-terminal pro-B-type natriuretic peptide

$\mathrm{O}_{2}$ ER: oxygen extraction

PACU: Post-Anaesthesia Care Unit

$\mathrm{PaCO}_{2}$ : carbon dioxide partial pressure

$\triangle P \mathrm{CO}_{2}$ : central venous-to-arterial PCO2 difference

$\mathrm{PaO}_{2}$ : oxygen partial pressure

$\mathrm{ScvO}_{2}$ : central venous oxygen saturation

SPAP: systolic pulmonary artery pressure

$\mathrm{SpO}_{2:}$ peripheral arterial saturation

SVI: stroke volume index

SVRI: systemic vascular resistance index

TRPG: tricuspid regurgitation systolic pressure gradient 
TTE: transthoracic echocardiography

$\mathrm{VO}^{2}$ : oxygen consumption

\section{Declarations}

Acknowledgements

Not applicable.

Authors' contributions

MCML this author helped in the conception and design of the study, acquisition, analysis and interpretation of data, writing and review of the article. VGF and NMG helped in the acquisition, analysis and interpretation of data, writing and review of the article.

JSM this author helped in the conception and design of the study, acquisition, analysis and interpretation of data and review of the article. JARM this author helped in the writing and review of the article.

All authors read and approved the final manuscript.

Funding

Not applicable.

Availability of data and materials

The datasets used and/or analyzed during the current study are available from the corresponding author on reasonable request.

Declarations

Ethics approval and consent to participate

The trial was approved by the Ethics and Clinical Research Committee of the Hospital Universitario de Canarias (Spain), and written consent was obtained from each patient.

Consent for publication

Not applicable.

Competing interests

The authors declare that they have no competing interests.

\section{References}


1. Katsoulis M, Benetou V, Karapetyan T, Feskanich D, Grodstein F. Pettersson-.

2. Kymmer $\mathrm{U}$, et al. Excess mortality after hip fracture in elderly persons from.

3. Europe. and the USA: the CHANCES project. Journal of Internal Medicine. 2017.

4. 281.: 300-310.

5. Roche JJ, Wenn RT, Sahota O, Moran CG. Effect of comorbidities and postoperative complications on mortality after hip fracture in elderly people: prospective observational cohort study. BMJ. 2005;331:1374-6.

6. Leier CV, Binkley PF. Parenteral inotropic support for advanced congestive heart failure. Prog Cardiovasc Dis. 1998;41:207-24.

7. Tanigawa T, Yano M, Kohno M, Takeshi Y, Takayuki Hisaoka K, Ono, et al. Mechanism of preserved positive lusitropy by AMPc-dependent drugs in heart failure. Am J Physiol Heart Circ Physiol. 2000;278:313-20.

8. Antoniades C, Tousoulis D, Koumallos N, Marinou K, Stefanadis C. Levosimendan: Beyond its simple inotropic effect in heart failure. Pharmacol Ther. 2007;114:184-97.

9. Nijhawan N, Nicolosi AC, Montgomery MW, Aggarwal A, Pagel PS, Warltier DC. Levosimendan enhances cardiac performance after cardiopulmonary bypass: a prospective, randomized placebocontrolled trial. J Cardiovasc Pharmacol. 1999;34:219-28.

10. De Hert SG, Lorsomradee S, Cromheecke S, Van der LindenPJ. The effects of levosimendan in cardiac surgery patientswith poor left ventricular function. Anesth Analg. 2007;104:766-73.

11. Harrison RH, Hasselblad V, Mehta RH, Levin R, Harrington RA, Alexander JH, et al. Effect of levosimendan on survival and adverse events after cardiac surgery: a meta-analysis. J Cardiothorac Vasc Anesth. 2013;27:1224-32.

12. Toller W, Heringlake M, Guarracino F, Algotsson L, L, Álvarez J, Argyriadou. H.

13. et al. Preoperative and perioperative use of levosimendan in cardiac surgery.

14. European expert opinion. Int J Cardiol. 2015;184:323-36.

15. Ponschab M, Hochmair N, Ghazwinian N, Mueller T, Plöchl W. Levosimendan infusion improves haemodynamics in elderly heart failure patients undergoing urgent hip fracture repair. Eur $\mathrm{J}$ Anaesthesiol. 2008;25:627-33.

16. Lee TH, Marcantonio ER, Mangione CM, Thomas EJ, Polanczyk CA, Cook EF, et al. Derivation and prospective validation of a simple index for prediction of cardiac risk of major noncardiac procedures. Circulation. 1999;100:1043-9.

17. Monnet X, Rienzo M, Osma D, Anguel N, Richard C, Pinsky MR, et al. Passive.

18. leg raising predicts. fluid responsiveness in the critically. Crit Care Med. 2006; 34.

19. -07 .

20. Cullen MW, Gullerud RE, Larson DR, Joseph Melton L III, Jeanne M. Huddleston. Impact of Heart Failure on Hip Fracture Outcomes: A Population-Based. J Hosp Med. 2011;6:507-12. 
21. Flancbaum L, Ziegler DW, Choban PS. Preoperative intensive care unit admission and hemodynamic monitoring in patients scheduled for major elective noncardiac surgery: a retrospective review of 95 patients. J Cardiothorac Vasc Anesth. 1998;12:3-9.

22. Nielsen DV, Algotsson L. Outcome of inotropic therapy: is less always more? Curr Opin Anaesthesiol. 2015;289:159-64.

23. Belletti A, Castro ML, Silvetti S, Greco T, Biondi-Zoccai G, Pasin L, et al. The effect of inotropes and vasopressors on mortality: a meta-analysis of randomized clinical trials. Br J Anaesth. 2015;115:65667.

24. Toufektzian L, Theodorou D, Larentzakis A, Misthos P, Katsaragakis S. Optimization of cardiac performance in chronic heart failure patients undergoing elective non-cardiac surgery. Curr Anaesth Crit Care. 2007;18:50-7.

25. Katsaragakis S, Kapralou A, Drimousis P, Markogiannakis H, Larentzakis A, Kofinas G, et al. Prophylactic preoperative levosimendan administration in heart failure patients undergoing elective non-cardiac surgery: A preliminary report. Hellenic J Cardiol. 2009;50:185-92.

26. Morelli A, Ertmer C, Pietropaoli P, Westphal M. Reducing the Risk of Major Elective Non-Cardiac Surgery: Is there a Role for Levosimendan in the Preoperative Optimization of Cardiac Function? Curr Drug Targets. 2009;10:863-71.

27. Lilleberg J, Nieminen MS, Akkila J, Heikkila L, Kuitunen A, Lehtonen L. Effects.

28. of a new calcium sensitizer, levosimendan, on haemodynamics, coronary blood.

29. flow and myocardial substrate utilization early after coronary artery bypass.

30. grafting. Eur Heart J. 1998; 19: 660-8.

31. $\mathrm{Ng}$ TM. Levosimendan, a new calcium-sensitizing inotrope for heart failure. Pharmacotherapy. 2004;24:1366-84.

32. Michaels AD, McKeown B, Kostal M, Vakharia KT, Jordan MV. Gerber IL.

33. Effects of. intravenous levosimendan on human coronary vasomotor regulation, left.

34. ventricular wall stress, and myocardial oxygen uptake. Circulation 2005; 111.

35. -9 .

36. Kivikko M, Lehtonen L. Levosimendan: a new inodilatory drug for the treatment of decompensated heart failure. Curr Pharm Des. 2005;11:435-55.

37. Slawsky MT, Colucci WS, Gottlieb SS, Greenberg BH, Haeusslein E, Hare J, et al. Acute hemodynamic and clinical effects of levosimendan in patients with severe heart failure. Study Investigators Circulation. 2000;102:222-7.

38. Morelli A, Teboul JL, Maggiore SM, Vieillard-Baron A, Rocco M, Conti G, et al. Effects of levosimendan on right ventricular afterload in patients with acute respiratory distress syndrome: A pilot study. Crit Care Med. 2006;34:2287-93.

39. Morelli A, De Castro S, Teboul JL, Singer M, Rocco M, Conti G. Effects of.

40. levosimendan on systemic. and regional hemodynamics in septic myocardial. 
41. depression. Intensive Care Med. 2005;31:638-44.

42. Levin R, Porcilem R, Salvagio F, Del Mazo C, Botbol A. Tanus E. Levosimendan.

43. reduces mortality in. postoperative low cardiac output syndrome after coronary surgery. J Clin Exp Cardiol. 2009;120:987-8.

44. Anastasiadis K, Polychronis A, Vranis K, Kleontas A, Asteriou C. Grosomanidis Effectiveness of prophylactic levosimendán in patients with impaired left ventricular function undergoing coronary artery bypassbgrafting: a randomized.

45. pilot study. Interactive Cardiovascular Thoracic Surgery. 2016;23:740-7.

46. Salottolo KM, Mains CW, Offner PJ, Bourg PW, Bar-Or D. A Retrospective Analysis of Geriatric Trauma Patients: Venous Lactate Is a Better Predictor of Mortality Than Traditional Vital Signs. Scand J Trauma Resusc Emerg Med. 2013;14:21-7.

47. Vallee F, Vallet B, Mathe O, Parraguette J, Mari A, Samii K, et al. Central venous-to-arterial carbón dioxide difference: An additional target for goal-directed therapy in septic shock? Intensive Care Med. 2008;34:2218-25.

48. Schwarte LA, Picker O, Bornstein SR, Fournell A, Scheeren TW. Levosimendan is superior to milrinone and dobutamine in selectively increasing microvascular gastric mucosal oxygenation in dogs. Crit Care Med. 2005;33:135-42.

49. Fries M, Ince C, Rossaint R, Bleilevens C, Bickenbach J, Rex S, et al. Levosimendan but not norepinephrine improves microvascular oxygenation during experimental septic shock. Crit Care Med. 2008;36:1886-91.

50. Parissis JT, Adamopoulos S, Antoniades C, Kostakis G, Rigas A. Kyrzopoulos S.

51. et al. Effects of levosimendan on circulating pro-inflammatory cytokines and soluble apoptosis mediators in patients with decompensated advanced heart failure. Am J Cardiol. 2004; 93:1309-12.

52. Smit-Fun V, Buhre WF. The patient with chronic heart failure undergoing surgery. Curr Opin Anaesthesiol. 2016;29:391-6.

53. Lilleberg J, Laine M, Palkama T, Kivikko M, Pohjanjousi P, Kupari M, et al. Duration of the haemodynamic action of a 24-h infusion of levosimendan in patients with congestive heart failure. Eur J Heart Fail. 2007;9:75-82.

54. Mebazaa A, Nieminen MS, Packer M, et al. Levosimendan vs dobutamine for patients with acute decompensated heart failure. SURVIVE JAMA. 2007;297:1883-91.

55. Lehtonen L, Mills-Owens P, Akkila J. Safety of levosimendan and other calcium sensitizers. J Cardiovasc Pharmacol. 1995;26:70-6.

56. Sosa Henríquez M, Segarra Sanchez MC, Limiñana Cañal JM, Hernández Hernández D, González Pacherco A. Betancor León P. Morbilidad y mortalidad de la fractura osteoporótica de la extremidad proximal del fémur tras un año de seguimiento. Med Clin (Barc). 1993;101:481-3.

\section{Figures}


Figure 1. Preoperative optimization protocol with levosimendan in the heart failure of the patient undergoing hip surgery.

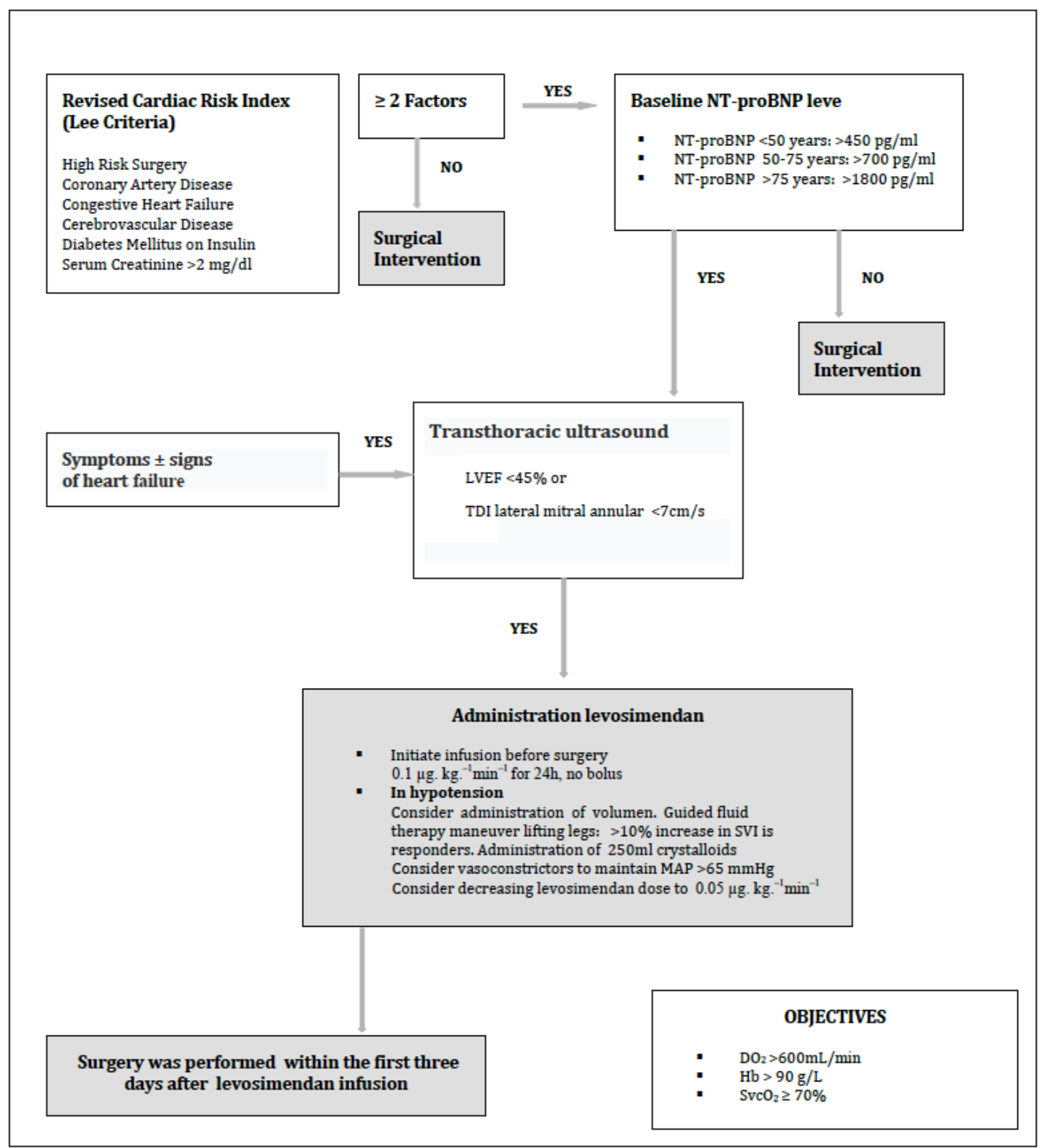

$\mathrm{DO}_{2}=$ oxygen delivery, $\mathrm{Hb}=$ haemoglobin, $L E V F=$ left ventricular dysfunction, $M A P=$ mean arterial blood pressure, $N T$-proBNP=N-terminal pro-B-type natriuretic peptide, $\mathrm{SvCO}_{2}=$ central venous oxygen saturation, $T D I=$ Tissue Doppler imaging..

\section{Figure 1}

Preoperative optimization protocol with levosimendan in the heart failure of the patient undergoing hip surgery 


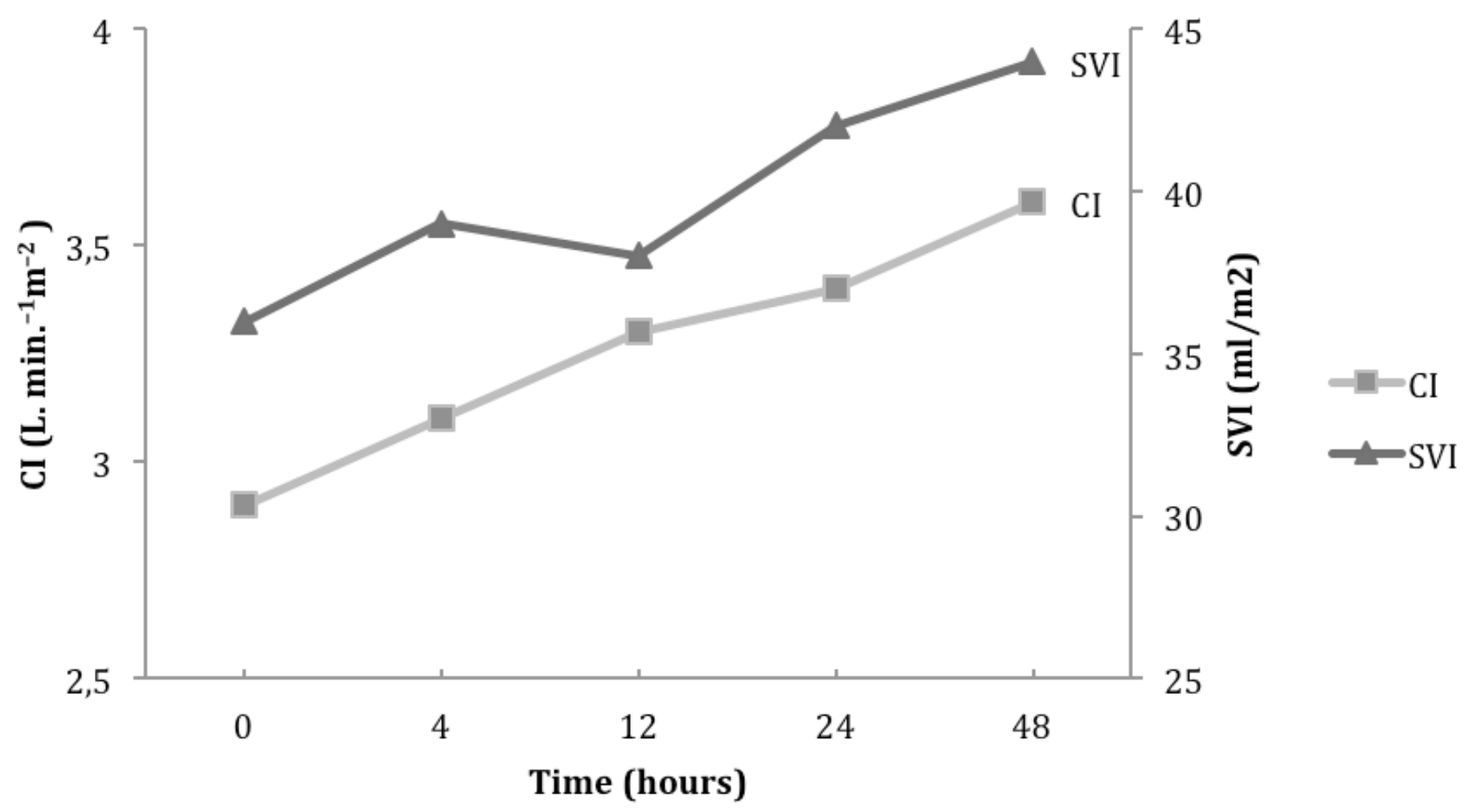

Figure 2

Changes in cardiac index (Cl) and stroke volume index (SVI) from baseline to 48 hour after start of levosimendan infusion.

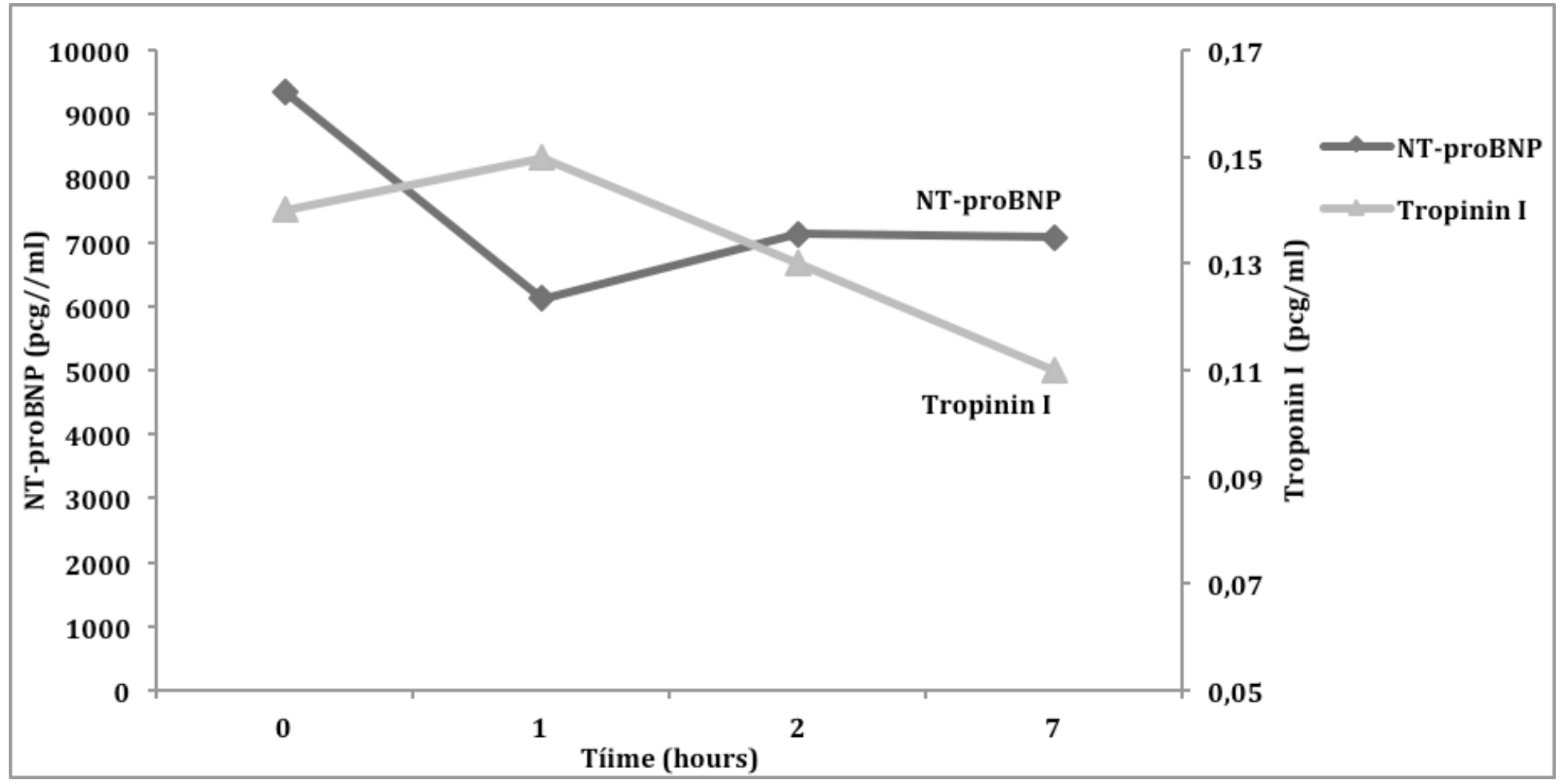

Figure 3 
NT-proBNP and troponin I changes during levosimendan infusion. 